\title{
Measurements of Penetration and Detoxification of PS II Herbicides in Whole Leaves by a Fluorometric Method
}

\author{
M. Voss, G. Renger, P. Gräber \\ Max-Volmer-Institut für Biophysikalische und Physikalische Chemie, \\ Technische Universität Berlin, Strasse des 17. Juni 135, D-1000 Berlin 12 \\ and C. Kötter \\ Schering AG, Pflanzenschutzforschung, D-1000 Berlin 65 \\ Z. Naturforsch. 39 c, $359-361$ (1984); received November 28, 1983 \\ Whole Leaves, Photosynthesis, Herbicide Penetration and Detoxification, Fluorometric Method \\ The effect of herbicides that inhibit the photosynthetic electron transport at the photosystem II \\ acceptor side has been analyzed in whole plants by using a fluorometric method. The data \\ reported indicate that the apparent variable fluorescence of the induction curve normalized to \\ the control value provides reliable information about the penetration rate and metabolic detoxi- \\ fication of PS II herbicides in whole plants.
}

\section{Introduction}

Substances that inhibit the photosynthetic electron transport at the acceptor side of system II (PS II) are widely used as herbicides (for review, see [1]). These compounds bind via non-covalent interaction with polypeptides functioning as apoenzyme for the primary and secondary plastoquinone $\left(\mathrm{Q}_{\mathrm{A}}\right.$ and $\mathrm{Q}_{\mathrm{B}}$, respectively). The polypeptides are exposed to the outer surface of the thylakoid membrane [2-4].

The efficiency of PS II-herbicides in whole plants does not only depend on the affinity to the target polypeptide but also on additional parameters like transport barriers or metabolic detoxification. Accordingly, chemicals acting as very potent PS IIinhibitors in isolated chloroplasts were found to be rather poor herbicides in plants [1]. This implies the necessity to analyze the effects in whole plants. The fluorescence induction caused by continuous illumination of moderate intensity reflects the redox state of $\mathrm{Q}_{\mathrm{A}}$ [5]. As fluorescence emission can be detected rather easily, various attempts have been reported recently to use fluorescence measurements as a simple analytical tool for the detection of herbi-

Abbreviations: Betanal ${ }^{\circledR}$ (phenmedipham), 3-methoxycarbonylaminophenyl-N-(3-methylphenyl)carbamate; DCMU, 3-(3,4-dichlorophenyl)-1,1-dimethylurea; Goltix ${ }^{\circledR}$ (metamitron), 3-methyl-4-amino-6-phenyl-1,2,4-triazine-5(4H)one; PS, photosystem; Pyramin ${ }^{\circledR}$ (pyrazon or chloridazon), 5-amino-4-chloro-2-phenylpyridazine-3-one; $\mathrm{Q}_{\mathrm{A}}$, primary quinone electron acceptor of photosystem II; $Q_{B}$, secondary quinone electron acceptor.

Reprint requests to Prof. Dr. G. Renger.

0341-0382/84/0500-0359 \$01.30/0 cide effects in whole plants [6-9]. Despite other interfering parameters, reliable results can be obtained, thus providing information about penetration and detoxification of PS II-herbicides [10]. The present study describes results obtained in different plants with PS II-herbicides by the use of a fluorometric method.

\section{Materials and Methods}

Plants (rape, spinach, Ipomoea and sugar beet) were grown in a phytochamber. The light/dark regime was $8 \mathrm{~h} / 16 \mathrm{~h}$ and the temperature $22^{\circ} / 16^{\circ} \mathrm{C}$. Radiation was supplied by fluorescent lamps (Osram $65 \mathrm{~W} / 20 \mathrm{R}$ ) at an intensity of $20 \mathrm{~W} / \mathrm{m}^{2}$. Fluorescence induction curves were measured with the equipment described in [11]. The time scale was appropriately selected so that the fluorescence rise in blocked centers was not resolved. Accordingly, the apparent variable fluorescence at the characteristic time $t_{\mathrm{m}}, F_{\mathrm{V}}\left(t_{\mathrm{m}}\right)$ normalized to the control value $F_{\mathrm{V}}$ (control) can be used as a qualitative measure of the inhibition degree (see [10]). Herbicides were sprayed on the upper leaf surface.

Phenmedipham was applied as the commercially available product Betanal ${ }^{\circledR}$.

\section{Results and Discussion}

Theoretical considerations [10] led to the conclusion that the apparent variable fluorescence normalized to the control value, $F_{\mathrm{V}}\left(t_{\mathrm{m}}\right) / F_{\mathrm{V}}$ (control), can be used as a qualitative measure of herbicide action in whole plants. It drops down if photosynthetic electron transport becomes blocked. 
In order to test the reliability of the fluorometric method, different rape leaves were treated with phenmedipham at a concentration corresponding to $1 \mathrm{~kg} / \mathrm{ha}$ and the ratio $F_{\mathrm{V}}\left(t_{\mathrm{m}}\right) / F_{\mathrm{V}}$ (control) measured as a function of time after herbicide application. The data in Fig. 1 show that the variations for different leaves of the same biotype are sufficiently small.

The fluorometric method can be used also to analyze the penetration and detoxification patterns of PS II-herbicides in different plants. DCMU was used for permeability studies in spinach leaves. $50 \mu 1$ of methanolic DCMU-solution were spread over a $1 \mathrm{~cm}^{2}$ leaf area and the fluorescence was measured at 5-10 min intervals. The results depicted in Fig. 2 indicate that at the lowest concentration only a small effect is observed. Obviously, the total herbicide amount is too small, so that the effective concentration in the chloroplasts of the plant cells is not sufficient for a significant degree of inhibition. At a 20 - and also at a 100-fold higher concentration a marked decrease of $F_{\mathrm{V}}\left(t_{\mathrm{m}}\right) / F_{\mathrm{V}}$ (control) is observed. The differences in the final level after $1 \mathrm{~h}$ treatment are probably due to limitations of the actual DCMU-concentrations in the chloroplasts, so that a complete blockage cannot be achieved at least at the lower concentrations.

The presented data show that the fluorometric method provides information about the rate of PS II-herbicide penetration in plants. A detailed

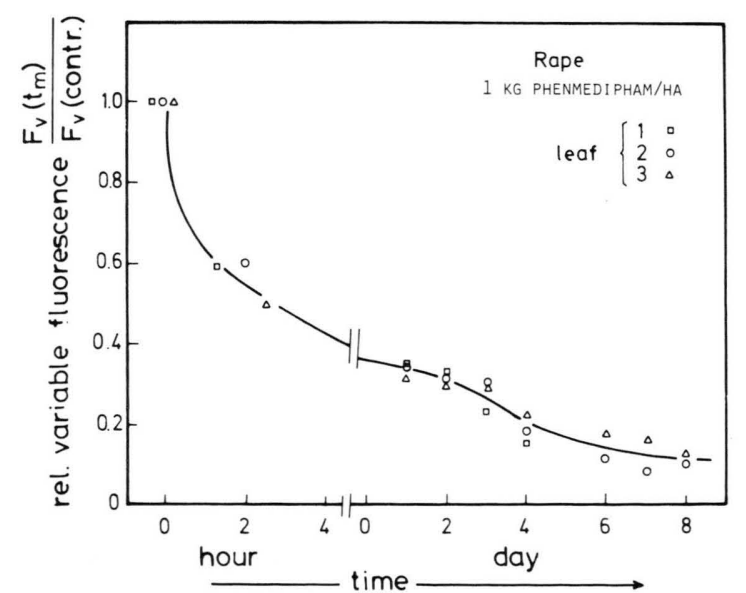

Fig. 1. Apparent variable fluorescence normalized to the control value, $F_{\mathrm{V}}\left(t_{\mathrm{m}}\right) / F_{\mathrm{V}}$ (control), as a function of time after application of phenmedipham in different rape leaves. Experimental conditions as in Materials and Methods.

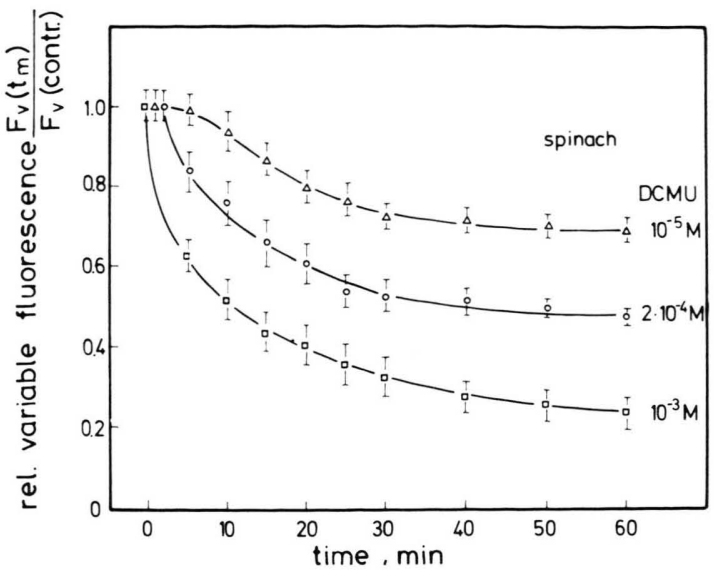

Fig. 2. Apparent variable fluorescence normalized to the control value, $F_{\mathrm{V}}\left(t_{\mathrm{m}}\right) / F_{\mathrm{V}}$ (control), as a function of time after DCMU treatment of spinach leaves. $50 \mu \mathrm{l}$ of a methanolic DCMU-solution were spread over a leaf area of ca. $1 \mathrm{~cm}^{2}$. Other experimental conditions as in Materials and Methods.

analysis of the penetration kinetics will be presented elsewhere.

The applicability of fluorometric methods for measuring herbicide detoxification kinetics is exemplified by results obtained with phenmedipham which are presented in Fig. 3 a. In Ipomoea leaves, phenmedipham caused a continuous decline of $F_{\mathrm{V}}\left(t_{\mathrm{m}}\right) / F_{\mathrm{V}}$ (control) with increasing time after foliar treatment with the herbicide (Fig. $3 \mathrm{a}$ ) indicating an irreversible and progressive blockage of PS II electron transport. In contrast, the same treatment of sugar beet (Fig. $3 \mathrm{~b}$ ) induced only a transient decrease of $F_{\mathrm{V}}\left(t_{\mathrm{m}}\right) / F_{\mathrm{V}}$ (control) which completely disappeared after sufficient recovery time. The different behavior is caused by a metabolic degradation of the active compound phenmedipham into $\beta$-Dglucopyranos-2-yl-sulfat-derivatives in sugar beet [12], whereas Ipomoea is lacking this capability. Similar results were obtained with PS II-herbicides (phenmedipham, metribuzin or chloridazon) in susceptible (soybean, dwarf bean, cotton) and resistant (sugar beet) plants $[10,11]$. The results obtained with the fluorometric method led to the same conclusions as those reached by using other analytical tools, but the performance of fluorescence measurements is much simpler. They provide a rapid and nondestructive method for the detection of herbicide detoxification. The data of Fig. $3 \mathrm{~b}$ also show that the detoxification rate is markedly slower than the penetration rate of the herbicide. 


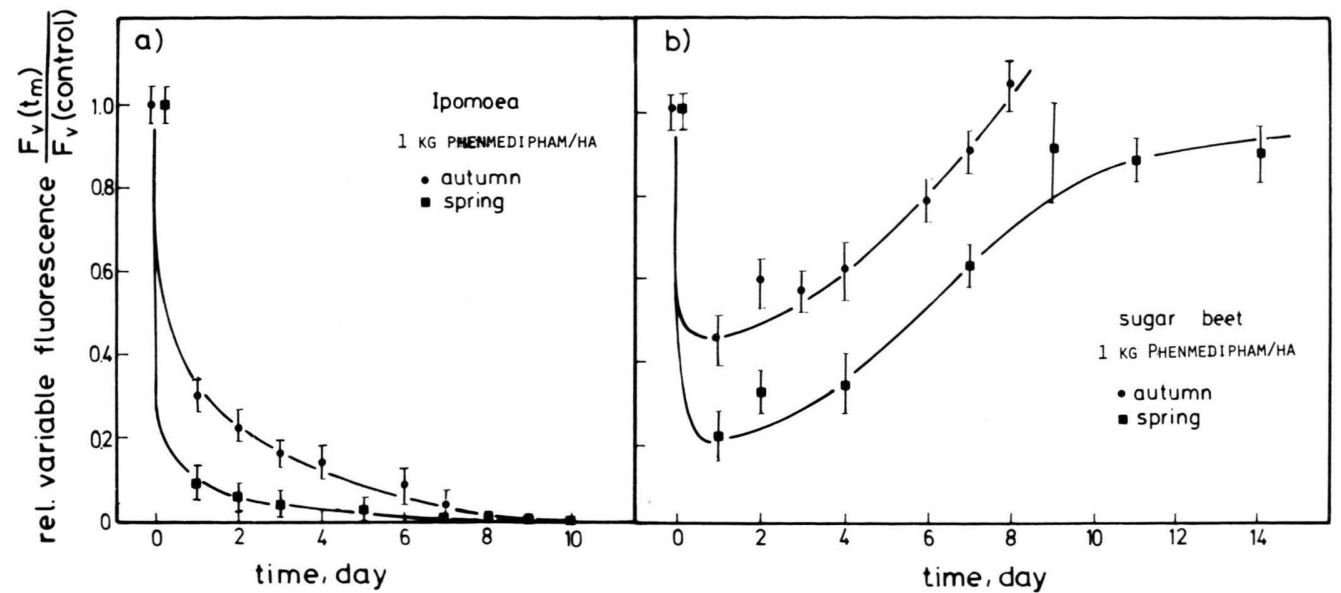

Fig. 3. Apparent variable fluorescence normalized to the control value, $F_{\mathrm{V}}\left(t_{\mathrm{m}}\right) / F_{\mathrm{V}}$ (control), as a function of time after application of phenmedipham in Ipomoea (a) and sugar beet (b) leaves. Experimental conditions as in Materials and Methods.

Further striking phenomena of Fig. 3 are the different susceptibilities of plants grown during spring and autumn, respectively. For the time being, this seasonal effect appears to be rather curious because the experiments were performed with plants of the same age which are grown in a phytochamber by using the same seeds. Even more pronounced seasonal variations are observed if the plants are grown in a greenhouse or in the field.

The seasonal phenomena observed with the phenmedipham-susceptible Ipomoea could perhaps be explained by penetration differences in spring- and autumn-time plants. The same phenomenon could

[1] C. Fedtke, Biochemistry and physiology of herbicide action, 1st Edn., Springer-Verlag, Berlin 1982.

[2] G. Renger, Biochim. Biophys. Acta 440, 287-300 (1976).

[3] A. Trebst, Z. Naturforsch. 34c, 986-991 (1979).

[4] K. Pfister and C. J. Arntzen, Z. Naturforsch. 34c, 996- 1009 (1979).

[5] L. M. N. Duysens and H. E. Sweers, in: Microalgae and Photosynthetic Bacteria, pp. 353-372, University of Tokyo Press, Tokyo 1963.

[6] U. Schreiber, R. Fink, and W. Vidaver, Planta 133, 121-129 (1977)

[7] N. R. Baker and M. Bradbury, in: Plants and Daylight Spectrum (H. Smith, ed.), pp. 355-373, Academic Press 1982. also be responsible for the resistant sugar beets, because a reduction of the penetration rate simultaneously with an invariant detoxification rate would give rise qualitatively to the differences observed in Fig. 3b. This assumption, however, remains to be confirmed experimentally.

\section{Acknowledgements}

The authors would like to thank Miss I. Gotsch for skillful technical assistance. The financial support by the Bundesministerium für Forschung und Technologie (KBF 46) is gratefully acknowledged.

[8] E. Cadahia, J. M. Ducruet, and P. Gaitlardon, Chemosphere 11, 445-450 (1982).

[9] E. P. Richard, Jr., J. R. Gross, C. J. Arntzen, and F. W. Slife, Weed Sci. 31, 361-367 (1983).

[10] M. Voss, G. Renger, C. Kötter, and P. Gräber, Weed Sci. (in press).

[11] M. Voss, G. Renger, and P. Gräber, Proc. VI. Int. Congr. Photosynthesis (C. Sybesma, ed.), Martinus Nijhoff/Dr. W. Junk Publishers, in press (1984).

[12] J. I. Celorio, Thesis TU Berlin D 83 (1983). 